\title{
Building a System Informative Abilities of Bachelors of Technical College
}

\author{
Tatyana Aleksandrovna Posyagina
}

\section{Andrey Vladimirovich Bondarev}

Irina Alekseevna Sapryko

\begin{abstract}
Kumertau Branch of Orenburg State University, Correspondence: Andrey Vladimirovich Bondarev, Kumertau Branch of the
\end{abstract} Orenburg State University, 2 per. Sovety, 3b, Kumertau, Russian Federation, 453300, E-mail: BondarevAV@kfosu.edu.ru

\section{Doi:10.5901/mjss.2015.v6n5s4p446}

\section{Abstract}

The purpose of this article is identification of pedagogical conditions of formation of system informative abilities of applied and academic bachelors of tuition by correspondence. For this purpose in article it is offered: model and a trajectory of formation of system informative abilities of bachelors of tuition by correspondence by sharing in technology of training of multidimensional and activity approach and the doctrine about approximate bases of actions of P. Y. Galperin, eventually, deepening of the theory of the developing training for modern reality. Where a pedagogical condition of performance of the above-named activity of students, authors note application of didactic multidimensional technology of professor V.E. Steinberg, namely expansion of its substantial part due to multidimensional submission of information on history of electrical equipment and the organization of deductive and synthetic logic of educational process with a support on a visual graphic framework of cognitive maps with multicode submission of information. Under such circumstances, the multidimensional organization of the base of knowledge of history of electrical equipment of the XIX century supported thanks to a visual (graphic) framework of a cognitive map allows to open more stoutly and more deeply continuity, interrelation and a complementarity of scientific information, it is more intelligible and simpler to state it to bachelors. In the modern interconnected, contradictory and roughly developing world, development of science and equipment is systemically connected with social, economic, historical, ecological processes. Creatively to solve actual scientific and technical problems, according to Federal State Educational Standard of higher education (FGOS VPO), the bachelor needs to comprehend deeply all these difficult interrelations of scientific and technical progress, to seize complete scientific outlook, ability creatively to apply dialectic methods in any sphere of the activity. In this regard ability of judgment of the past for the best understanding of the present and the future is a task which the discipline "Electrical equipment history" and at the certain level-each bachelor studying it is urged to solve

Keywords: didactic multidimensional technology; a cognitive map with multicode submission of information "History of electrical equipment of the XXI century"

\section{Introduction}

Historically, in Russia new transformations in the field of the higher education after its accession in 2003 to the European educational community began. Further according to the order of the Ministry of Education and Science of the Russian Federation (No. 556 of 09.11.2009) the Federal state educational standard of higher education (FGOS VPO), in particular, in the direction of training of the academic bachelors 140400.62 "Power industry and electrical equipment" was approved. In this document it is emphasized that the competence defined within the all-European process of formation of the European system of qualifications as "ability of the person independently to apply various elements of knowledge and abilities in this or that context" becomes the key term FGOS VPO. Introduction in "The concept of long-term social and economic development of the Russian Federation for the period till 2020" the concepts "applied bachelor degree" was the subsequent step. Practically, the Ministry of Education and Science of the Russian Federation recommends to higher education institutions to enter educational programs of an applied bachelor degree since 2013. This direction is called by authors of the document one of ways, the first among a set, on increase of availability of the quality education conforming to requirements of innovative development of economy of Russia and, according to a number of researchers (Anischenko, 2011; Afanasova, 2008; Esenina, 2010; Serpents, 2003; Zverev, 2007), to modern requirements of society. The idea fully corresponds to trends of a state policy in education as the president and the government demand to adjust training of highly skilled workers and to strengthen an applied component in the higher education that employers hadn't to finish learning university graduates. 
Therefore, relevance of this research, is caused by the existing contradiction:

Between the social order of modern higher education for training of applied and academic bachelors within the existing federal state educational standards (FSES) and deficiency of theoretical and pilot studies of their preparation.

This contradiction defined the research objective consisting in identification of pedagogical conditions of formation of system informative abilities of applied and academic bachelors (below bachelors) tuition by correspondence.

For achievement of a goal we offer deepening of the theory of the developing training for modern reality. Especially, according to D. I. Feldstein (Feldstein, 2011): "It is possible to be proud of that in domestic psychology and pedagogical science was headed for the developing training believing understanding long ago; ascension from abstract to concrete, based on the principles of theoretical thinking". This statement from the methodological point of view assumes deepening of the theory of the developing training by joint application of multidimensional and activity approach and the doctrine about approximate bases of actions of P. Y. Galperin.

Novelty of research is that we changed a subject of the research of formation of system informative abilities of students mechanics of technical college conducted earlier on the example of teaching constructional materials science (Kolesnikova, 2003; Posyagina, 2009; Popkov, 2004), to an example of teaching history of electrical equipment, for formation of system informative abilities of applied and academic bachelors of the direction of preparation 140400.62 "Power industry and electrical equipment" of tuition by correspondence.

\section{Literature Review}

Pedagogical condition of performance of the above-named activity of students we offer application of didactic multidimensional technology of professor V. E. Steinberg (Steinberg, 2002), namely expansion of its substantial part due to multidimensional submission of information on history of electrical equipment and the organization of deductive and synthetic logic of educational process with a support on a visual graphic framework of cognitive maps with multicode submission of information, we will stop on its description in more detail below.

Pedagogical conditions are requirements from which it is necessary to proceed when performing a task (Dneprov, 2006). If a task is formation of system informative abilities of bachelors of technical college of tuition by correspondence, a pedagogical condition for its performance is preparation of the educational and methodical materials considering features of the adults who are trained. We will open pedagogical conditions, model and a trajectory of process of formation of system informative abilities of the bachelor of technical college of tuition by correspondence.

In view of the designated favorable conditions of training of adults at tuition by correspondence, we will stop on researches where pedagogical conditions of interaction of the teacher and student from the point of view of dependence of the maintenance of approximate bases of action and the formed skills of students were analyzed. So, Y. G. Fokin (2002) notes that in domestic practice of inservice training the flow charts of formation of skills intending for mass training of students, namely operators of a difficult technique were developed and focused on the instructors who don't have pedagogical knowledge. Rather concrete recommendations containing in these documents allowed them to provide fast and faultless development by trainees of works with the difficult equipment. For our research the judgment about an orientation and visual (graphic) controllability of formation of operational skills has special value. The object which the student has to seize in the form of a subject, process, the phenomenon, the law or rule is represented schematically, shares on part, and connection between them is established that promotes his distinct perception, understanding and answers cash opportunities of the student. These parts on the scheme are represented so that their interaction is easily traced and, the action rationality thereby is provided. The order of use of instructions is shown. Such scheme is very simple when studying and allows not to remembering the even just received explanation since its main contents is also submitted on this to it.

A. Y. Shurupov (2003) considers the pedagogical conditions of formation of complex abilities of pupils including the organization of main types of educational activity by tool didactics. F. F. Arduvanova (2006) analyzes the didactic means of model type which are carrying out functions of approximate bases of actions at the solution of tasks. S. A. Arslanbekova (2003) stops on pedagogical conditions of the developing potential of mathematics including approximate bases of actions with expanded functions for support of main types of educational activity and ways of their application. Process of preparation and training at high school was object of the researches given above and introduced in practice. We will note the obvious fact that pedagogical conditions at the higher school considerably differ towards increase in volume and complexity of a training material, but laws of psychology of knowledge are uniform. Thus the principle of continuity of scientific knowledge is expressed in our research that universal logiko-semantic models (Steinberg, 2001) for the general secondary education are basis of cognitive maps with multicode representation of knowledge (on the example of materials science), but the concept of multidimensional display of reality of V. E. Steinberg (1999) is uniform 
and doesn't depend on age of trainees.

Therefore, concepts of multidimensional display of reality of V. E. Steinberg are submitted by the way of overcoming of an one way of thinking of students which is shown in impossibility of deduction in the realized part of thinking at the same time descriptive (processed) and operating types of information (instructions, orientations etc.). Undoubtedly, noting a certain contribution of the above-named researchers, we offer the informative potential of association multidimensional and activity approach together with the doctrine about approximate bases of actions to present models of formation of system informative abilities of bachelors of technical colleges in the form, allocating thus system impact on the bachelor in everyone, noted above, parts of activity: substantial, motivational, approximate, executive.

\section{Method}

The substantial part is a basis of educational activity as for the sake of assimilation of the contents and she will be organized as that. As a way of systematization of technical knowledge their internal basis is accepted: unity of the principles of materiality of the world and development his dialecticians. Fair and convincing idea by the teacher of training materials in the form of cognitive maps with multicode submission of information with the dosed uncertainty provides basic possibility of management of the follow-up independent activity of the bachelor of tuition by correspondence. In other words, the substantial part of activity of the bachelor consists of multidimensional representation of a training material and the organization of ways of thinking (deduction and induction) the bachelor thanks to a graphic framework of cognitive maps with multicode submission of information.

The motivational part of educational activity as an organizational stage plays a central role. Experience, erudition and belief of the bachelor, installation on perception of evident representation of communications and the relations in structure of a subject by means of a cognitive map with multicode submission of information, the logician of creation of its contents lay the foundation for extent of understanding of requirements, understanding of the purposes and problems of educational activity.

Purpose of cognitive maps with multicode submission of information is in approximate part of educational activity that they direct cogitative activity of the bachelor in the course of perception of information, the analysis and application of knowledge. In didactic process they carry out function of approximate bases of educational actions and a verbal context of modeling. Otherwise, cognitive maps connect static properties of presentation and dynamic properties of approximate bases of action to multicode submission of information. Their methodical justification consists in addition of the standard methods of research of a subject of studying with the new approaches following from the concept of multidimensional and semantic spaces presented earlier. We will distinguish from them anthropological to design of methods and means of tool didactics: nature corresponding character of cognitive maps with multicode submission of information in relation to morphological features of a brain. Priority of this approach consists that semantic fractals as cognitive maps with multicode submission of information of representation of knowledge facilitate activity of the teacher thanks to coordination of external and internal plans of cognitive activity, coordination of the first and second alarm systems of the person, the right and left cerebral hemispheres. In turn we will call multidimensional approach to representation of a training material, namely: presentation, completeness, logicality enough the stable fundamental technical knowledge necessary for understanding, assimilation and orientation in a flow of the increasing information, and also for acquisition of the corresponding professional skills and abilities. Further the essence of didactic-tool approach to the organization of educational activity of bachelors-correspondence students-programming of operations of the analysis and synthesis, and also a support of external and internal plans for the training and technological models necessary at design and modeling of knowledge, explications and visualization of problem situations, search of their decision follows. The lastinvariant-approach to representation and use of elements of didactic systems and processes consists in expansion of multidimensional models of representation of knowledge, in repetition of limited number of operations for formation of semantic groups and "granulation" of knowledge, coordination and ranging, semantic binding, a reformulation.

We will address to executive part of educational activity in which use of cognitive maps with multicode submission of information directly provides transformation of objects of educational activity and receiving result since fractal simulated training material stimulates consecutive process of bit-by-bit formation of abilities to carry out cogitative activity of the bachelor in the course of perception, thus through cognitive representation the understanding of essence of subject technical matters is reached.

Use of cognitive maps with multicode submission of information in control part is directed not only on check of correctness of results, but also on tracking of the course of performance of activity, i.e. on the solution of a problem of check of compliance to its drawn-up plan, correlation of a product of activity with its purpose. It is expedient to estimate 
the informative abilities of bachelors formed in control part of educational activity on quality of allocation of structural elements of knowledge, completeness of disclosure of interrelations of elements, possession of concepts and regularities of discipline, including intersubject communications. The assessment of formation of systemacity of knowledge of bachelors by these criteria can testify as skill of systematization of the acquired knowledge is developed, and also the motivation to training and professional and personal development of the bachelor is initiated. Control of correctness of the solution of a task means a consciousness orientation on own activity, on abstraction and synthesis of the carried-out actions. In case of detection of a mistake, a deviation from the correct course of action there is a need of correction of activity of the bachelor.

Thus, basic novelty of a didactic form of cognitive visualization on the basis of structuring, binding and folding of a training material, represents the way of overcoming of "one way" of thinking of bachelors which is shown in impossibility of deduction in the realized part of thinking at the same time descriptive (processed) and operating types of information (instructions, orientations etc.). It allows the teacher to simplify process of an explanation of the most difficult for perception educational audience of sections of discipline, and to bachelors to gain profound knowledge of difficult subjects of discipline in more evident and available form that was difficult.

Further, we will consider taking into account the aforesaid, a set of trajectories of formation of system informative abilities of the bachelors of technical college set (see Figure 1) in system of coordinates: results of educational activity (knowledge, abilities, skills) from training process (the network plan schedule of tuition by correspondence in higher education institution: adjusting session, independent work of the bachelor, laboratory examinations). Initially, a condition of successful formation of system informative abilities on the basis of cognitive maps with multicode representation of knowledge is their interference with skills of disciplines of a natural-science cycle. We attach significance to initial proficiency of bachelors of tuition by correspondence. By G. K. Selevko's definition is (Selevko's, 2005) the level and quality of knowledge, skills of students, a state and formation of real educational activity - "abilities to study", methods of independent search of knowledge and self-education. Thus dependence of the considered trajectory on initial proficiency of bachelors of tuition by correspondence are defined by us as conditions of formation of maxima and minima in an interferential picture. Where the trajectory "And" defines entry conditions of a maximum of an interferential picture which final point corresponds to an appreciation of level of formation of systemacity of knowledge of bachelors, in turn, the trajectory "In" defines entry conditions of a minimum which final point corresponds to a low mark, thus dispersion of initial knowledge, the formed skills is presented in fig. by 1 sizes $\delta 3, \delta \mathrm{Y}, \delta \mathrm{H}$. Thus, trajectories "And" and "In" form the corridor tunnel limiting deviations of personal trajectories dependent not only from the training conditions, but also from psychophysiological characteristics which are trained. Besides development and the offer on the market of educational services of a set of trajectories gives trained opportunity of the maximum satisfaction of inquiries and a choice of an independent way of training.

Further we will explain a form of trajectories "And" and "In", representing stages of formation of skill of systematization. We accept V. Okon's position (1990), the formation of intellectual skill allocating five stages:

1) An explanation for students of value of ability to carry out action;

2) The formulation and repetition of rules on the basis of the available knowledge of students to gain ability or skill of the formed action;

3) Display by the teacher of process of work which students have to carry out;

4) The first works of students under a constant control of the teacher;

5) Systematic and independent exercises of students on the basis of the acquired abilities in skill, and skills subsequently, under favorable circumstances pass into a habit.

However, owing to specifics of tuition by correspondence, we bring the replacement: instead of five stages V. Okonya, we accept three stages, integrating them and connecting with the network plan schedule of tuition by correspondence in higher education institution:

1) Formation of ability to carry out action of systematization according to P. Y. Galperin (adjusting session);

2) Performance of exercises of systematization on the basis of the acquired ability (independent work of the bachelor during the intersession period);

3) Transfer of skill of systematization in new conditions (laboratory examinations).

Further we will stop in more detail on each of three allocated sites of a trajectory of formation of system informative abilities of the bachelor of technical college of tuition by correspondence.

Site 1: At the first stage of formation of ability to carry out action of systematization according to P. Y. Galperin, the trajectory form in fig. 1 represents the step line symbolizing five stages of formation of intellectual action of systematization on the basis of P. Y. Galperin's theory (1966):

The first stage P. Y. Galperin calls introduction and motivational (VM in fig. 1). At this stage action isn't carried out 
yet, it is only prepared. The bachelor gets acquainted with action and conditions of its performance, having before himself an approximate basis of action in the form of a cognitive map with multicode submission of information. At this stage the bachelor has to understand logic of the mastered systematization action, estimate possibility of its performance. At this stage also the problem of motivation of action is solved. It becomes by dialogue, involving bachelors in orientation process, using various methods of activization, bringing elements of a professional orientation in the content of action. Quite often bachelors put understanding as the operational purpose of educational activity, considering that if the trainee understood, so he learned. But the purpose of training is an action of systematization, and it can't learn, having only understood in what it consists. Even supervision over actions of other people (both teachers, and other students) isn't enough, though it is useful. For assimilation of activity it needs to be executed most. It also assumes other four stages: a stage of the material (materialized) action, a stage of speech action, a stage of speech action about itself, a stage of intellectual action.

At the second stage-a stage of formation of actions in the material (materialized) form (MD in fig. 1) action of systematization is carried out in the same form with expansion of all operations entering it: idealization, comparison, analysis, synthesis, abstraction, specification. Thus, opportunity for the bachelor to acquire the content of action, and for the teacher to check performance of each operation entering action is created. For simplification of the transfer of action to a speech form, everything is useful to pronounce, formulate the carried-out operations in the speech that is carried out practically, having before itself a cognitive map with multicode submission of information. Let it don't confuse adults; laws of psychology extend both on children, and on adults.

The third stage-a stage of speech action (RD in Figure 1) systematization-is directed on action formation as speech. At this stage all elements of action are presented in the form of the socialized speech, action takes place further generalization, but remains yet not automated and not reduced. Speech action, as well as material, surely has to be mastered in expanded form, by means of a cognitive map with multicode submission of information. All operations entering systematization action have to not only get a speech form, but also to be mastered.

The fourth stage is a stage of performance of speech action about itself (RDS in Figure 1). Feature of this stage is that the trainee, as well as at the previous stage, pronounces all process of the solution of a task, but does it about itself, without external manifestation, silently. As a matter of fact, it is the same speech, as earlier, but it isn't socialized any more, it is carried out in the internal plan not available to the external observer. At the beginning action according to the main characteristics differs in nothing from previous, but then starts being reduced quickly, reaching automatism. Reduction and automation of action of systematization testify that its formation passes to the fifth, final stage-a stage of intellectual action (UD in Figure 1).

Action quickly is reduced and automated, becomes inaccessible to introspection. It turns into skill.

Thus, we assume as a basis P. Y. Galperin's theory at the microlevel of formation of intellectual actions by means of a separate cognitive map with multicode submission of information.

During adjusting session it is necessary to explain to bachelors value of ability of systematization of a training material. For this purpose the teacher has to show a place and a role of discipline in science and production, prospects of its development and history of its emergence. On end of this stage, the first works of bachelors under a constant control of the teacher. The bachelor should apply consciously acquired rules. This performance, however, meets in the beginning the obstacles connected with the interference described above the constant control over initial actions of bachelors is therefore necessary.

In the conditions of tuition by correspondence, the teacher, during adjusting session at lecture, uses presentation of cognitive maps with multicode submission of information for an explanation of a training material. It is important to emphasize the compelled organization of a way of thinking (deduction and induction) of the bachelor thanks to a visual (graphic) framework of cognitive maps. Similar exercises are a preparatory stage to independent work of the bachelor during the intersession period (See Figure 1), performance of a control task.

Site 2: The second stage consists in systematic and independent exercises of systematization of bachelors on the basis of the acquired abilities and conducts to transformation into skill. Already during assimilation, actions of bachelors become conscious, based on the corresponding rules. Skill is gained as a result of systematic and independent repetition of earlier acquired ability, and in the course of repetition new kinds of activity have to be respectively fixed. That to bring skills to perfection, long and laborious exercises are required. Skill is formed on the basis of performance of a certain system of algorithmic exercises.

Algorithmic exercise is based on the exact instruction and has such set of operations and rules of their alternation by means of which, since some basic data it is possible to solve an objective. Simplicity of the operations included in algorithm has to leave a place for reflections and conscious activity taking into account the level of preparation and development of the bachelor. A point of control of the second stage (independent work of the bachelor during the 
intersession period) is performance and protection of examination. The teacher pays attention to extent of awareness of generality of action of systematization by the bachelor, whether it catches a community, whether finds points of application for transfer, whether the developed and generalized way of action of systematization sees in a new situation the moments allowing transferring to it. Thus, results of protection of examination are basic data for the following stage of a trajectory of formation of system informative abilities of the bachelor of technical college of tuition by correspondence.

Site 3: At the third stage the teacher has a possibility of correction of result of independent work of the bachelor. When performing laboratory and practical works, the teacher has opportunity to repeat and fix skill of systematization, applying cognitive maps with multicode submission of information repeatedly to an explanation by bachelors of the studied phenomena. The tilt angle in fig. of 1 considered trajectory of the third stage is more, than the second, it symbolizes the formation process speed which directly depends on personal contact of the bachelor and the teacher, noted above. A control point in end of a trajectory is examination in discipline.

Eventually, basic novelty of a didactic form of cognitive visualization on the basis of structuring, binding and folding of a training material, represents the way of overcoming of an one way of thinking of bachelors which is shown in impossibility of deduction in the realized part of thinking at the same time descriptive (processed) and operating types of information (instructions, orientations etc.). It allows the teacher to simplify process of an explanation of the most difficult for perception educational audience of sections of discipline, and to bachelors to gain profound knowledge of difficult subjects of discipline in more evident and available form that it wasn't represented possible at inductive and analytical logic of educational process of explanatory and illustrative training earlier. The offered trajectory of formation of system informative abilities can develop into a habit of the bachelor to think systemically at development of other disciplines and in further professional activity.

We will note optimum conditions and factors for formation of system informative abilities of bachelors of technical college of tuition by correspondence.

1) Pedagogical function of cognitive maps with multicode submission of information as tutorials of bachelors of tuition by correspondence in creating an adequate image of the studied fragment of reality and to expand sensual experience, to open essence of the studied phenomena, to establish connection and the relations between parts whole, thus to bring it to appropriate scientific generalizations. 


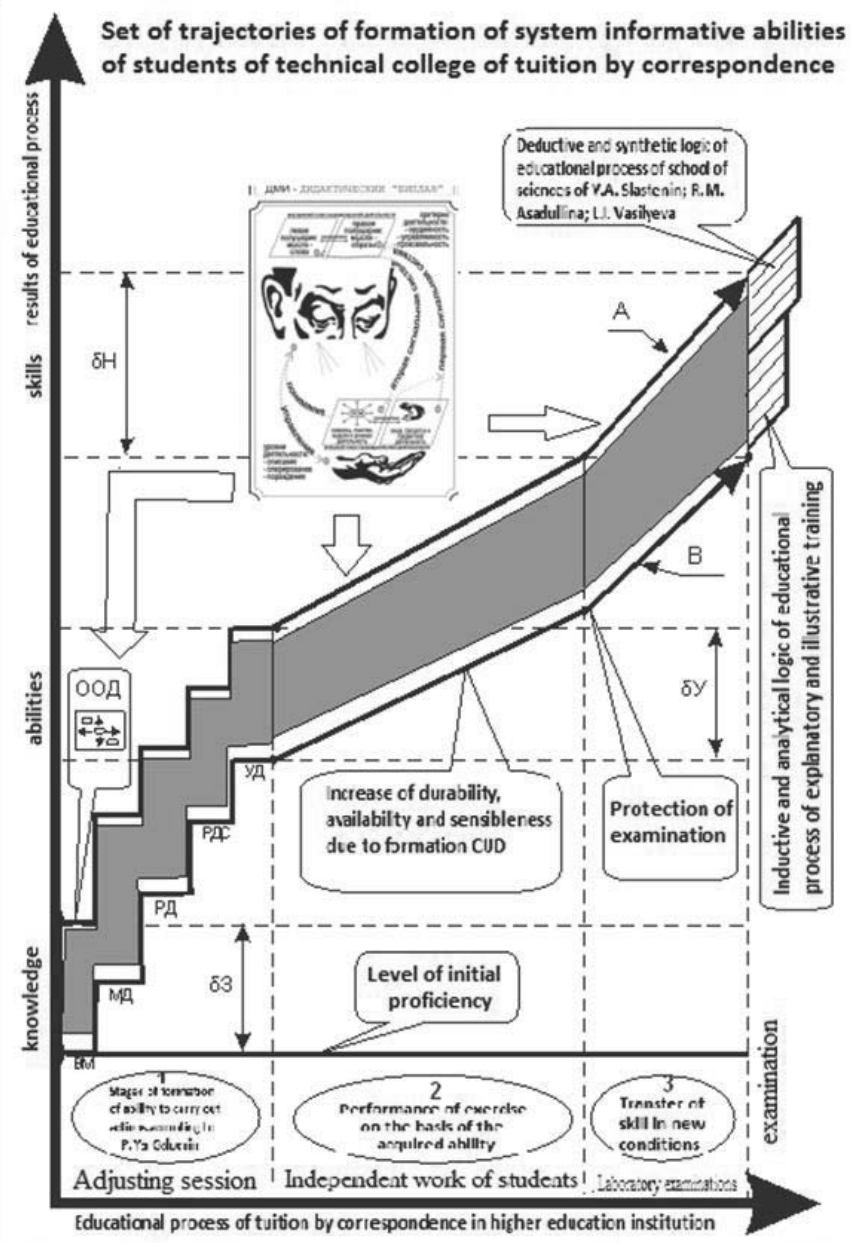

Trajectories " $A$ " and " $E$ " - correspond to a raximum anc a nininum of initial proficiency; $O C D$ approsinate bases of action; CUD - ways of intellestral actions; VM - an introcuston and motivational stage; $\mathrm{MD}$ - a stage cf the materialized action; RD - a stage of speesh action; RDS - a stege of speech acticn about itself; UD - a stage of irtellectual action

Figure 1. Set of trajectories of formation of system informative abilities of bachelors of technical college of tuition by correspondence

2) The model of formation of system informative abilities of cogitative activity of bachelors of higher education institution when studying disciplines of a technical cycle is realized by means of cognitive maps with multicode submission of information. Informative potential of development of the bachelor is realized thanks to system didactic influence in each part of educational activity:

- Substantial, consisting of orientation to essence of a training material, visual demonstration of fundamental unity and specifics of distinctions in structure and properties of the discipline reached by multicode representation of a training material;

- Motivational, including experience, erudition and belief of the bachelor, installation on perception of evident representation of communications and the relations in structure of a subject, to logician of creation of the contents as a basis for increase of extent of understanding of requirements, understanding of the 
purposes and problems of educational activity;

- The indicative, specifying the content of the concept "cognitive map" with multicode representation information which is understood as mental representation of the bachelor about the logical organization of a training material, about schematical display of relationships of cause and effect in object of research, that is about the actions of deduction and induction supported thanks to a visual (graphic) framework;

- The executive, stimulating consecutive process of bit-by-bit formation of abilities cogitative activity of the bachelor in the course of perception, thus intelligence and generality is reached by structure and coherence of a training material.

3) The trajectory of formation of system informative abilities of bachelors of higher education institution includes stages:

- Formation of ability to carry out action of systematization on to P. Y. Galperin (adjusting session);

- Performance of exercises of systematization on the basis of the acquired ability (independent work of the bachelor);

- Transfer of skill of systematization in new conditions (laboratory examinations). The offered trajectory of formation of system informative abilities has to develop into a habit of the bachelor to think systemically at development of other disciplines and in further professional activity.

\section{Results}

Figuratively we will develop the considered period of history of electrical equipment of the XIX century in a centrifugal ("solar") way by means of a cognitive map (see Figure 2). As O. N. Veselovsky and Y. A. Shneyberg's researches (1993) chronologically allocated four stages of history of development of electrical equipment of the XIX century; four coordinates of a cognitive map represent them graphically, as measurement of time of the XIX century. At the same time, it is a cluster of knots where names of outstanding scientists, the founders of the theory of electricity of this period united in group thanks to what the cognitive map becomes multidimensional are entered. Then in intercoordinate sectors we place elements of those opening which defined the most obviously scientific and technical progress of the XIX century with the help of multicode submission of information, led to large-scale social changes and in many respects predetermined modern development, as advanced countries, and practically all population of the globe. We will stop below at these opening.

In the first quarter of interaxal space we place the image of force of interaction of two positive charges, established in 1785 by Sh. Kulon and symbolizing formation of an electrostatics (till 1800). Here we will note, allocated with I. A. Glebov (1999), one of characteristic regularities of development of technology - historical conditionality of the major opening and inventions. So within many centuries, up to the last quarter for the XVIII scientist only the phenomena of static electricity were known, however industrial revolution of the XVIII century gave a powerful spur to development of various branches of science, including science about electricity. In this regard transition from high-quality supervision of the electric and magnetic phenomena, to establishment of quantitative communications and regularities of the first scientific theories was quite natural step on the way of studying of the electric phenomena: magnetic phenomena of $U$. Gilbert (1600); electricity, as "non-material liquid" of B. Franklin (1747); "radio" M. V. Lomonosov (1752). These theories served as first "bricks" for a laying of the base of electrical equipment, its scientific bases.

In the second quarter of interaxal space we place G.'s experiment by X shown in 1820. An oersted on supervision of action of current on a magnetic needle, the excited great interest among the scientific different countries which received in their works further deepening and establishment of communications between the electric and magnetic phenomena. The beginning of this period is marked by creation of "a Volta of a column" - the first electrochemical generator (1789), and as a result, emergence of the closed chain of direct electric current, further research of regularities of its thermal, chemical and magnetic properties. Opening of Ampere's law (1826) and Biot-Savart-Laplace (1820) was the major achievements here; theoretical researches of electric chains by G. Om (1827). Thus, during this period (18001830) in studying of the electric phenomena certain success was achieved, in them starts being interested more and more not only physicists, but also the scientists trying (and not unsuccessfully) to apply electricity for practical purposes.

In the third quarter of interaxal space we place model of the electric motor of a direct current of the student (subsequently professors) Pisa university of Antonio Pachinotti (1841-1912), for the first time in 1860 the ring anchor which offered a design. As only the galvanic cell was the only reliable and studied source of the electric power to the middle of the XIX century, it is natural, the first electrical machines of a direct current began to develop.

First of all, the most significant event of this period was opening of the phenomenon of electromagnetic induction (1831) by M. Faraday and irrespective of will of the inventor there was an objective need for a product of his creativity. 
These years various designs of electrical machines and devices are developed, laws Laziness and Kirchhoff are formulated, the first sources of electric lighting, the first electroautomatic devices are created, the electric equipment arises. So above-named researchers $\mathrm{O}$. N. Veselovsky and Y. A. Shneyberg (6) allocated four stages of development only to model of the generator of a direct current: Piksiya's brothers (1832); B. S. Jacobi (1842); "Alliance" (1849); G. Wilde (1863); Gram (1870). Thus, "pioneer" period of history of electrical equipment (1830-1870) it was expressed in that with opening of the phenomenon of electromagnetic induction, long evolution of a configuration of magnetic system of electrical machines began, the main ratios between the geometrical sizes, magnetodriving forces and induktion weren't found out yet.

At the same time, electrotechnical devices didn't go beyond laboratories, there was no rather powerful and economic source of electric energy and the mass consumer yet. As it was told above, by 1870 such source was created. 15-20 years following this date passed as years of origin of the main electrotechnical devices of a mass industrial and household purpose, as years of formation of new branch of equipment. It was the "heroic" period of history of electrical equipment.

In the fourth quarter of interaxal space as a symbol of practical formation of electrical equipment, we place a type of power plant of a direct current on Fontanka River in St. Petersburg (1886) which supplied with the electric power of a direct current the area of Nevsky Avenue. Here in development of technology we will give the 90th years of the XIX century which were marked by uncompromising struggle of two companies as an example of resolution of conflicts. On the one hand it was General Electric defending interests of Edison who is the adherent of use of a direct current. It was opposed by the Westinghouse Electric company creating the production on the basis of numerous patents of Nikola Tesla in the field of alternating current. This period became history of the industry, as "The period of transformer fights". However the developing production demanded the complex solution of the most difficult scientific and technical problem: economic transfer of the electric power on a long distance and creations of the economic and reliable electric motor meeting requirements of the industrial electric drive. This problem was successfully solved on the basis of multiphase, in particular three-phase systems of alternating current. P. N. Yablochkov's idea about the centralized production and distribution of the electric power construction of the central power plants of alternating current was realized, began.

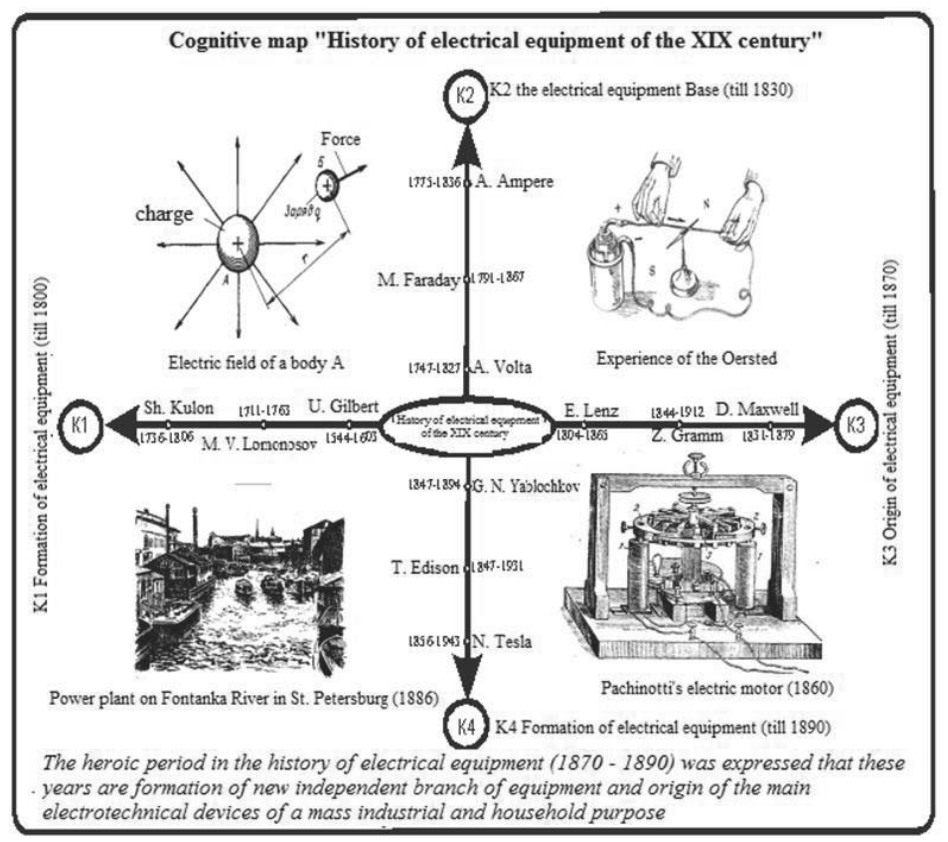

Figure 2. Cognitive map

In summary it is possible to tell that, the considered form of a cognitive map with multicode submission of so large-scale information, contains essential degree of uncertainty of operation of "a semantic granuleness" of information of basic 
knot-a name of the giving-out scientist. Therefore paying a tribute of respect to their personality, using encyclopedic data (Yuzhakov, 1900; Gerasimov, Grudinskiy, \& Beetles, 1980) and topological property of a cognitive map, for inquisitive students is created opportunity to comprehend nodal questions of history of development of electrical equipment, individualizing this process.

Thus the logic of comparison of dates, names and subjects of opening of the great researchers of electrical equipment of the XIX century marked above on a cognitive map with multicode submission of information and biographic data lead us to some additional remarks.

\section{Discussion}

First, the level of equipment is defined by degree of knowledge of laws of the nature and therefore the equipment is indifferent to a nationality: the modern transformer or an electric motor created at the Russian or American plant; in principle don't differ from the friend. As for the direction, rates of development of technology that social and economic structures have more noticeable impact on it.

Secondly, in the conditions of modern scientific and technical revolution social responsibility of the engineer and scientist extraordinary increased in consequences of the activity. After all, as it was already noted above, the capacities created by the person become capacities, commensurable with that, which develop geophysical and space by forces. Therefore at design and operation of engineering objects integrated system approach, the account not only economic indicators, but also social, ecological criteria is necessary. For implementation of such integrated approach profound versatile knowledge is necessary. Now so difficult and perfect cars, devices and devices that on a trope of the academician V. Legasov (2007) are created: "If earlier we protected the person from equipment, improving safety measures, now it is necessary to protect also equipment from the person, from his incompetence of professional and psychological unpreparedness at management of enormous capacities and high-speed automatic devices".

Thus, it is possible with sufficient definiteness to tell that the multidimensional organization of the base of knowledge of history of electrical equipment of the XIX century supported thanks to a visual (graphic) framework of a cognitive map allows to open more stoutly and more deeply continuity, interrelation and a complementarity of scientific information, it is more intelligible and simpler to state it to bachelors. In the modern interconnected, contradictory and roughly developing world, development of science and equipment is systemically connected with social, economic, historical, ecological processes. Creatively to solve actual scientific and technical problems, according to FGOS VPO, the bachelor needs to comprehend deeply all these difficult interrelations of scientific and technical progress, to seize complete scientific outlook, ability creatively to apply dialectic methods in any sphere of the activity. In this regard ability of judgment of the past for the best understanding of the present and the future is a task which the discipline "Electrical equipment history" and at the certain level—each bachelor studying it is urged to solve.

\section{Conclusion}

It is prompt and contradictory the changing world imposes new requirements to the personality, her intellectual development and professional qualification today. We stand at the origins of creation of a new education system. In the Concept of modernization of Russian education for the period till 2020 it is emphasized that "the main task of the Russian educational policy is ensuring modern quality of education on the basis of preservation of its fundamental nature and compliance to actual and perspective needs of the personality, society and the state". Moreover, the history of a development of education testifies to priority of the doctrine among other human activities that especially became obvious in the come XXI century. The person, at last, began to realize that the main danger to his existence consists not so much in global crises, even not so much in imperfection him, how many in the increasing distance between rates of changes in surrounding reality and in its inner world. Adequately to answer time calls, training of the people, competent of a certain area, capable to apply the knowledge in the changing conditions, ability to join in continuous self-training throughout all life is necessary. It demands from the individual of ability to study, organize the training, and from the teacher thus to improve a technique of teaching difficult technical disciplines. This research doesn't apply for exhaustive permission mentioned in is mute aspects of formation of system informative abilities of students of technical college. Results of research showed prospects of further development of a problem, in particular, use of hypertext multimedia technology in cognitive maps as navigators of knowledge, adaptation of results of research for various categories of students, etc. 


\section{References}

Arduvanova, F. F. (2006). Scientific and methodical ensuring exercise book approach in training. The abstract of the thesis on competition of an academic degree of Candidate of Pedagogical Sciences. Yekaterinburg: Publishing house of Dews.

Arslanbekova, S. A. (2003). Realization of the developing potential of natural and mathematical disciplines on the basis of design and technological approach (on the example of mathematics). The abstract of the thesis on competition of an academic degree of Candidate of Pedagogical Sciences. Ufa: BSPU

Anishchenko, V. A. (2011). The theory strengthened by practice-one of the main conditions of successful implementation of the training programs. Messenger of a construction complex (Vol. 3, p. 55). St. Petersburg: JSC VSK.

Afanasova, D. K. (2008). Features of competence-based approach in training of the economist in mathematics. Secondary professional education. Moscow.

Yuzhakov, S. N. (Ed.). Big encyclopedia: The dictionary of public data on all branches of knowledge (pp. 1900-1909). SPb.: Education.

Veselovsky, O. N. (1993). Sketches on stories of electrical equipment. Moscow: Publishing house of MEI.

Galperin, P. Y. (1966). Psychology of thinking and the doctrine about stage-by-stage formation of intellectual actions. Moscow: Science.

Glebov, I. A. (1999). History of electrical equipment. Moscow: Publishing house "Science".

Dneprov, S. A. (2006). Pedagogics in terms and concepts. Omsk: Publishing house of OMGU.

Yesenina, E. Y. (2010). The concept of creation of programs of an applied bachelor degree in system of professional education of the Russian Federation Educational policy. Moscow: JSC Viva-Star printing house.

Zmeyov, S. I. (2003). Andragogic: Bases of the theory and technology of training of adults. Moscow: PER SE.

Zverev, S. V. (2007). Competitiveness of the graduate as social and pedagogical problem. Secondary professional education (Vol. 6, pp. 61-62).

Kolesnikova, I. A. (2003). Bases of an andragogic. Moscow: Academy center.

Legasov, V. A. (2007). Chemistry. Power. Safety. Moscow: Publishing house "Science".

Okon, V. (1990). Introduction to the general didactics. Moscow: High School.

Popkov, V. A. (2004). Didactics of the higher school. Moscow: Publishing center "Academy".

Posyagina, T. A. (2009). Formation of system informative abilities of students of technical college: The thesis on competition of an academic degree of Candidate of Pedagogical Sciences. Ufa.

Selevko, G. K. (2005). Technologies of the developing education. Moscow: Scientific research institute of school technologies.

Feldstein, D. I. (2011). Psychology and pedagogical bases of modern education. Professional education (Vol. 2, pp. 2-7). Capital.

Fokin, Y. G. (2002). Private technique of teaching basic subject matters of psychology and pedagogical training of teachers of the higher school. Moscow: The experimental center of retraining and professional development of teachers of technical universities and engineering higher education institutions of MGTU of N. E. Bauman.

Shurupov, A. Y. (2003). Development of complex educational abilities of pupils by means of tool didactics (on the example of physics). The abstract of the thesis on competition of an academic degree of Candidate of Pedagogical Sciences. Yekaterinburg.

Steinberg, V. E. (2001). Tool technologies of training: terminological and didactic aspects. Conceptual framework of pedagogics and education. Yekaterinburg: Publishing house of "SV-96".

Steinberg, V. E. (1999). Didactic multidimensional technology (theory and practice). Ufa: Publishing house of BIRO.

Steinberg, V. E. (2002). Didactic multidimensional tools: Theory, method, practice. Moscow: National education.

Zhukova, L. A., Gerasimov, V. G., \& Grudinsky, P. G. (1980). The electrotechnical reference book. Moscow: Energy. 